\title{
Mansikkalajikkeiden talvenkestävyyden mittaaminen
}

\author{
Leena Lindén ${ }^{1)}$ ja Timo Hytönen ${ }^{2)}$ \\ ${ }^{1)}$ Soveltavan biologian laitos, C-talo, PL 27,00014 Helsingin yliopisto, leena.linden@ helsinki.fi \\ ${ }^{2)}$ Soveltavan biologian laitos, C-talo, PL 27, 00014 Helsingin yliopisto, timo.hytonen@ helsinki.fi
}

\section{Johdanto}

Talvenkestävyys on yksi suomalaisen mansikanviljelyn keskeisistä ongelmista. Heikosta talvehtimisesta seuraa satomäärien suuri vuotuinen vaihtelu, mikä haittaa tuotannon järkiperäistä kehittämistä ja suunnittelua. Viljelyyn kaivataan jatkuvasti uusia, entistä satoisampia, taudin- ja kuljetuksenkestäviä mansikkalajikkeita. Korvaavien lajikkeiden käyttöönotto edellyttää tietoa niiden talvenkestävyydestä meidän ilmastossamme. Tähänastiset talvenkestävyystietomme perustuvat monivuotisiin kenttäkokeisiin, talvivauriohavaintoihin ja käytännön kokemuksiin. Talvenkestävyyttä, ja sen tärkeintä osatekijää, kylmänkestävyyttä, voidaan nykyään tutkia entistä tehokkaammin, säädellyissä oloissa tehtyjen kylmäkäsittelyiden ja vauriomittausten avulla.

Tämän tutkimuksen tavoitteena oli kehittää mansikan talvenkestävyyden mittaamiseen luotettava ja perinteisiä kenttäkokeita nopeampi menetelmä. Tutkitut menetelmät olivat (1) karaisu-purku-uudelleenkaraisu -ohjelma, (2) pitkäaikainen kylmäsäilytys ja (3) pellolla kasvavien taimien kylmänkestävyyden mittaaminen. Näiden, laboratoriossa tehtyjä mittauksia hyödyntävien menetelmien tuloksia verrattiin viljelykokemusten antamiin tietoihin ja kenttäkokeiden tuloksiin. Tutkimus oli osa maa- ja metsätalousministeriön rahoittamaa hanketta "Vadelman ja mansikan talvenkestävyyden parantaminen lajikevalinnan ja viljelytekniikan keinoin", jonka loppuraportissa (Palonen ym. 2001) on yksityiskohtainen selostus tutkimuksesta ja sen tuloksista.

\section{Aineisto ja menetelmät}

Tutkimus toteutettiin Helsingin yliopiston kasvintuotantotieteen (nykyisin soveltavan biologian) laitoksella vuosina 1998-2001. Ensimmäisenä vuonna kokeissa käytettiin viittä jo viljelyssä olevaa, talvenkestävyydeltään tunnettua lajiketta: 'Jonsok', 'Honeoye', 'Senga Sengana', 'Korona' ja 'Bounty'. Toisen vuoden kokeissa oli mukana kolme uutta kotimaista jalostetta: 91054019 ('Hella' x 'Glima'), 91110007 ('Bogota' x 'Rubino') ja 91062123 ('Hella' x 'Redgauntlet') sekä verrannelajikkeena 'Jonsok'. Testattavat taimet olivat kesällä pistettyjä, juurtuneita rönsypistokkaita. Syyskuun ajan taimia säilytettiin ulkona talveentumisen käynnistämiseksi. Kylmäkäsittelyt aloitettiin loka-marraskuussa.

\section{Karaisu-purku-uudelleenkaraisu -ohjelma}

Taimia pidettiin aluksi kaksi viikkoa $+1^{\circ} \mathrm{C}$ :ssa (karaisu), minkä jälkeen ne vietiin viikoksi +10 tai $+15^{\circ} \mathrm{C}$ :seen (karaistuneen tilan purku) ja lopuksi vielä kahden viikon ajaksi takaisin $+1^{\circ} \mathrm{C}$ : seen (uudelleenkaraisu). Taimien kylmänkestävyys mitattiin karaisukäsittelyn alkaessa sekä karaisun, purkukäsittelyn ja uudelleenkaraisun päättyessä. Ensimmäisenä vuonna kylmänkestävyys mitattiin myös yhden viikon karaisun jälkeen. Kylmänkestävyysmittaukset tehtiin pakastamalla pystyjuurakot viiteen kahden asteen portain alenevaan testilämpötilaan $\left(-4 \ldots-12^{\circ} \mathrm{C}\right.$ tai $\left.-6 \ldots-14^{\circ} \mathrm{C}\right)$.

Juurakoiden pakkaskäsittelyssä saamat vauriot mitattiin kasvutestillä; turve-hiekkaan istutettuja juurakoita pidettiin neljä viikkoa kasvihuoneessa $\left(+20^{\circ} \mathrm{C}\right.$, valojakso 9 tai $\left.16 \mathrm{~h}\right)$, minkä jälkeen laskettiin juurakoista kasvaneiden uusien lehtien ja juurten lukumäärät. Lopuksi pystyjuurakot halkaistiin ja niiden elävyys mitattiin solukoiden ruskettumisen perusteella. Taimien elinvoimaa kuvaava kasvuindeksi saatiin laskemalla yhteen lehtien ja juurten saman genotyypin kontrollitaimiin suhteutetut lukumäärät sekä ruskettumisen astetta kuvaava luku.

\section{Pitkäaikainen kylmäsäilytys}

Ensimmäisenä koevuonna taimia säilytettiin $1-12$ vrk joko -4 tai $-6^{\circ} \mathrm{C}: n$ lämpötilassa. Taimet vietiin säilytykseen kokonaisina, alkuperäisissä pistokaskennostoissaan ja näytteitä otettiin pois pakkasesta 
vuorokauden välein. Toisena vuonna säilytysaika oli $1-26$ vrk ja lämpötila joko -6 tai $-8^{\circ} \mathrm{C}$. Ennen säilytyksen alkua taimista poistettiin lehdet ja juuret ja paljaat pystyjuurakot pakattiin muovipusseihin kosteaan talouspaperiin käärittyinä. Näytteenottoväli oli kaksi vuorokautta.

Sulatuksen jälkeen juurakoiden kylmäsäilytyksessä saamat vauriot mitattiin kasvutestillä (5-6 vk, $+20^{\circ} \mathrm{C}$, valojakso 14 tai $16 \mathrm{~h}$ ) ja juurakoiden ruskettumisen perusteella. Kasvuindeksiin laskettiin lehtien tai lehtien ja juurten suhteelliset lukumäärät sekä ruskettumista kuvaava luku.

\section{Pellolla kasvavien taimien kylmänkestävyyden mittaaminen}

Taimet istutettiin mataliin, mustalla muovilla katettuihin harjuihin syyskuun alussa. Koe järjestettiin lohkoittain satunnaistettuina. Taimet istutettiin ensin kaksinkertaisiin, avopohjaisiin $12 \mathrm{~cm}: \mathrm{n}$ muoviruukkuihin, jotka istutettiin paririveihin pellolle. Muoviruukkujen käyttö helpotti taimien nostoa jäätyneestä maasta talvella (Palonen ja Lindén 2001). Peltotaimimenetelmää testattiin vain yhtenä vuonna. Taimia nostettiin kylmänkestävyysmittauksiin tammi-, maalis- ja huhtikuun alussa.

Maasta noston ja sulatuksen jälkeen taimista leikattiin lehdet ja juuret ja pystyjuurakot pakastettiin neljään kahden asteen portain alenevaan testilämpötilaan $\left(-6 \ldots-12^{\circ} \mathrm{C}\right)$. Pakkasvauriot mitattiin kasvutestillä (4-6 vk, $+20^{\circ} \mathrm{C}$, valojakso 14 tai $16 \mathrm{~h}$ ) ja juurakoiden ruskettumisen perusteella. Kasvuindeksiin laskettiin uusien lehtien ja juurten suhteelliset lukumäärät sekä ruskettumista kuvaava luku.

\section{Tilastolliset analyysit}

Kasvutestien tulokset käsiteltiin kaksi- tai kolmisuuntaisella varianssianalyysillä. Keskiarvojen väliset erot paikannettiin Fisherin testillä (riskitaso $\mathrm{P}<0,05$ ). Elävyysmittausten tulokset analysoitiin logit-malleilla pitäen 'Jonsokia' kontrollina, johon muita genotyyppejä verrattiin.

\section{Tulokset ja tulosten tarkastelu}

\section{Karaisu-purku-uudelleenkaraisu -ohjelma}

Kokeessa tutkittiin mansikan genotyyppien kylmänkestävyyttä, karaistumisnopeutta, karaistuneen tilan purkautumisalttiutta ja uudelleenkaraistumiskykyä. Tavoitteena oli selvittää, antaako karaistumisominaisuuksia mittaava menetelmä luotettavan kuvan genotyyppien talvenkestävyydestä.

Kasvutestin tulokset osoittivat, että ensimmäisenä vuonna tutkittujen viiden mansikkalajikkeen kylmänkestävyydessä ei ollut eroja lämpötilakäsittelyiden alkaessa $(\mathrm{P}=0,080)$. Lajikkeet erosivat toisitaan viikon $(\mathrm{P}=0,044)$ ja kahden viikon karaisun $(\mathrm{P}<0,001)$ sekä purkukäsittelyn $(\mathrm{P}<0,001)$ jälkeen. Uudelleenkaraisukäsittelyn vaikutuksista ei saatu tuloksia ensimmäisenä koevuonna, koska osa taimista sairastui tyvimätään kasvutestin aikana. 'Bounty' karaistui hitaasti ja vähemmän kuin neljä muuta lajiketta. 'Korona' säilytti kylmänkestävyytensä $+10^{\circ} \mathrm{C}: \mathrm{n}$ lämpötilassa 'Bountya', 'Jonsokia' ja 'Honeoyeta' paremmin. Myös 'Senga Senganan' kestävyys oli purkukäsittelyn jälkeen parempi kuin 'Jonsokin' ja 'Honeoyen'. - Elävyysmittausten perusteella 'Korona' oli keskimäärin eri lämpötilakäsittelyissä kylmänkestävämpi $(\mathrm{P}=0,014)$ ja 'Bounty' vähemmän kestävä $(\mathrm{P}=0,047)$ kuin 'Jonsok'. 'Senga Sengana' ja 'Honeoye' eivät eronneet 'Jonsokista'.

Ensimmäisenä vuonna tutkituista lajikkeista 'Jonsok' tiedetään käytännön kokemuksen perusteella talvenkestävimmäksi ja 'Honeoye' arimmaksi (Matala 1994 ja 1998). Muut kolme lajiketta sijoittuvat kestävyydeltään näiden välille (Matala 1994 ja 1998, Dalman ja Matala 1997). Karaisu-purku-uudelleenkaraisu -ohjelma ei kyennyt erottamaan edes arinta 'Honeoyeta' kestävimmästä 'Jonsokista'. Menetelmä osoitti kuitenkin 'Bountyn' 'Jonsokia' aremmaksi, mikä vastaa käytännön kokemuksia.

Toisena vuonna tutkittujen jalosteiden kylmänkestävyydessä ja karaistumisominaisuuksissa ei ollut eroja kasvutestien eikä elävyysmittausten perusteella. Yksikään jalosteista ei myöskään eronnut verrannelajikkeesta 'Jonsok'. Tutkittujen uusien jalosteiden talvenkestävyydestä on vasta vähän tietoa. MTT:n kaksi vuotta jatkuneissa kenttäkokeissa jaloste 91054019 on talvehtinut heikommin kuin 91110007 ja 91062123 (T. Hietaranta, henkilökohtainen tiedonanto). Myös Viikissä 91054019 on ensimmäisen satokauden jälkeen talvehtinut heikommin kuin 91110007, 91062123 ja 'Jonsok' (Hytönen 2001). Karaisupurku-uudelleenkaraisu -ohjelma ei kyennyt ennustamaan tällaisia eroja. 


\section{Pitkäaikainen kylmäsäilytys}

Kylmänkestävyyttä mitataan yleensä pakastamalla näytteet portaittain alenevaan lämpötilaan, jossa näytteitä säilytetään 30 minuutista muutamaan tuntiin (esim. Sakai ja Larcher 1987). Vaihtoehdoksi tälle menetelmälle on esitetty testiä, jossa mitataan, miten pitkän aikaa kasvit kestävät valittua pakkaslämpötilaa. Tällaista, solukoiden kuivuudensietokykyä testaavaa menetelmää on toistaiseksi sovellettu syysviljojen talvenkestävyyden mittaamiseen Kanadassa (Thomas ym. 1988, Gusta ym. 1997). Käsillä olevassa tutkimuksessa selvitettiin, antaako pitkäaikaiseen kylmäsäilytykseen perustuva testi luotettavan kuvan mansikkalajikkeiden talvenkestävyydestä Suomen oloissa.

Kaikki mansikkalajikkeet sietivät säilytyksen $-4^{\circ} \mathrm{C}$ :ssa hyvin. Pisimpäänkään varastoiduissa taimissa ei ollut vakavia vaurioita. Ensimmäisenä vuonna kokonaisina pakastetut taimet kestivät hyvin myös $-6^{\circ} \mathrm{C}$ :n lämpötilaa; vain 10 kokeen kaikkiaan 600:sta taimesta kuoli 12 vuorokauden varastoinnin aikana. Tutkittujen lajikkeiden pitkäaikaisen kylmäsäilytyksen sietokyvyssä ei ollut eroja kummassakaan lämpötilassa. Tulokset antoivat kuitenkin aihetta olettaa, että $-6^{\circ} \mathrm{C}: n$ säilytys kykenisi pidempään jatkettuna osoittamaan lajike-eroja.

Toisena vuonna mansikoista pakastettiin paljaat pystyjuurakot ja säilytysaikaa pidennettiin 26 vuorokauteen. Tällöin säilytys $-6^{\circ} \mathrm{C}$ :ssa osoitti jalosteen 91062123 kasvutestin perusteella aremmaksi kuin kaksi muuta jalostetta ja 'Jonsok' $(\mathrm{P}<0,001)$. Elävyysmittausten perusteella jalosteet 91054019 ja 91062123 olivat kumpikin 'Jonsokia' arempia $(\mathrm{P}=0,037)$. Alemmasta, $-8^{\circ} \mathrm{C}: n$ lämpötilasta ei saatu tuloksia, koska kaikki juurakot olivat kuolleet jo ensimmäisen säilytysvuorokauden aikana.

Toisen vuoden tulokset $-6^{\circ} \mathrm{C}: n$ säilytyksestä vastasivat MTT:n (T. Hietaranta, henkilökohtainen tiedonanto) ja Viikin (Hytönen 2001) kenttäkokeista saatuja alustavia talvenkestävyystuloksia. Lisäksi tulokset olivat yhtäpitäviä tämän tutkimuksen kolmannen menetelmän, pellolla kasvavien taimien kylmänkestävyystulosten kanssa.

\section{Pellolla kasvavien taimien kylmänkestävyyden mittaaminen}

Kylmänkestävyyttä pidetään tärkeimpänä mansikan talvenkestävyyteen vaikuttavana tekijänä (Harris 1970, 1973). Käsillä olevassa tutkimuksessa haluttiin selvittää, voidaanko kentällä kasvavien genotyyppien kylmänkestävyydessä osoittaa eroja, jotka ennustaisivat niiden talvenkestävyyttä Suomen oloissa.

Sekä kasvu- että elävyystestien perusteella jalosteet 91054019 ja 91062123 olivat keskimäärin yli mittausajankohtien vähemmän kylmänkestäviä kuin 'Jonsok'. Kaikki genotyypit olivat kestävimpiä tammikuussa, jolloin ne myös erottuivat toisistaan parhaiten. 'Jonsokin' sekä jalosteiden 91054019 ja 91110007 kestävyys väheni tasaisesti tammikuusta huhtikuulle. Jaloste 91062123 oli vielä maaliskuussa yhtä kestävä kuin keskitalvella; se oli menettänyt tammikuisen kestävyyden tasonsa vasta huhtikuussa. Huhtikuun mittauskerralla kylmänkestävyydessä oli eroja lohkojen välillä. Loivasti viettävän rinteen yläosan lohkossa taimet olivat vähemmän kestäviä kuin alarinteen lohkoissa. Ylärinteen lohkossa myös genotyyppien väliset kestävyyserot ilmenivät selvimmin: 91054019 ja 91062123 olivat 'Jonsokia' arempia ja lisäksi 91054019 oli arempi kuin 91110007.

Pellolla kasvavien taimien kylmänkestävyystulokset vastasivat MTT:n (T. Hietaranta, henkilökohtainen tiedonanto) ja Viikin (Hytönen 2001) kenttäkokeista saatuja alustavia talvenkestävyystuloksia. $\mathrm{Ne}$ olivat myös yhdenmukaisia pitkäaikaisen kylmäsäilytyksen tulosten kanssa. Peltotaimien mittaamisesta saadut tulokset osoittivat, että genotyyppien karaistumiskyvyssä ja karaistuneen tilan purkautumisessa oli eroja, vaikka niitä ei karaisu-purku-uudelleenkaraisu -ohjelmalla voitu todentaa.

\section{Johtopäätökset}

Karaisu-purku-uudelleenkaraisu -menetelmää ei voi sellaisenaan suositella mansikkalajikkeiden talvenkestävyyserojen testaamiseen. Ilmeisesti käsillä olevassa tutkimuksessa käytetty lämpötilaohjelma ja/tai näytteiden käsittelytekniikka eivät sovi mansikan karaistumisominaisuuksien mittaamiseen. Menetelmällä ei kyetty kumpanakaan koevuonna edes tyydyttävästi osoittamaan lajikkeiden ja jalosteiden välisiä kestävyyseroja. Mansikkalajikkeiden käyttäytymistä keinotekoisissa lämpötilakäsittelyissä on tutkittu varsin vähän. Dzabicin (1997) opinnäytetyössään esittämät tulokset muistuttavat tässä raportoitavien 
kokeiden tuloksia: hyvin talvenkestäväksi tunnettu 'Jonsok' ei keinotekoisissa karaisukäsittelyissä erottunut aremmista lajikkeista.

Pitkäaikainen kylmäsäilytys antoi lupaavia tuloksia. Gustan ym. (1997) mukaan subletaali, pitkäaikainen kylmästressi jäljittelee talven kasveille aiheuttamia rasituksia todenmukaisemmin kuin kylmänkestävyyden mittaamiseen yleensä käytetty moniportainen testi. Pitkäaikainen kylmäsäilytys sopisi käytettäväksi mansikkalajikkeiden valinnassa ja jalostusohjelmissa. Kasvunsa päättäneitä, karaistuneita pistokastaimia käytettäessä säilytys on parasta toteuttaa $-5 \ldots-6^{\circ} \mathrm{C}$ :ssa. Säilytystä on jatkettava 2-4 viikkoa yhden vuorokauden näytteenottovälein. Tehokkain lämpötila-aika -yhdistelmä löytyy vasta, kun menetelmästä kertyy enemmän kokemuksia.

Myös kentällä karaistuneiden taimien kylmänkestävyyden mittaaminen näyttäisi sopivan talvenkestävyyserojen osoittamiseen lajikevalinnan ja jalostuksen yhteydessä. Parhaiten lajikkeet erottuvat keskitalvella, kun niiden kylmänkestävyys on suurimmillaan. Kaksinkertaisiin ruukkuihin istuttamalla taimet saadaan helposti irrotetuksi jäisestä maasta. Kaiken kaikkiaan tulokset osoittavat, että mansikkalajikkeiden talvenkestävyyttä voidaan ennakoida mittaamalla niiden kykyä sietää pitkäaikaista kylmästressiä tai mittaamalla pellolla karaistuneiden taimien kylmänkestävyyttä keskitalvella.

\section{Kirjallisuus}

Dalman, P. \& Matala, V. 1997. The effect of cultivation practices on the overwintering and yield of strawberry. Acta Hort. 439, vol. 2: 881-885.

Dzabic, M. 1997. Virkninger av klimafaktorer på vekst, blomstring og herdighet hos jordbaer (Fragaria x ananassa Duch.). Cand. Scient. oppgave i plantefysiologi. Universitet i Troms $\varnothing$. Institutt for biologi og geologi. 54 p.

Gusta, L.V., O'Connor, B.J. \& MacHutcheon, M.G. 1997. The selection of superior winterhardy genotypes using a prolonged freeze test. Can. J. Plant Sci. 77: 15-21.

Harris, R.E. 1970. Laboratory technique for assessing winterhardiness in strawberry (Fragaria x ananassa Duch.). Can. J. Plant Sci. 50: 249-255.

Harris, R.E. 1973. Relative hardiness of strawberry cultivars at three times of the winter. Can. J. Plant Sci. 53: 147152.

Hytönen, T. 2001. Mansikan talvenkestävyyden mittaaminen. Pro gradu -tutkielma, Helsingin yliopisto, soveltavan biologian laitos. $55 \mathrm{p}$.

Matala, V. 1994. Mansikan viljely. 2. p. Helsinki , Puutarhaliitto. 263 p.

Matala, V. 1998. Mansikan lajikekokeet käytännön viljelmillä. Mikkeli, Maatalouden tutk.keskus, Luonnonvarojen tutk., Ekologinen tuotanto. $36 \mathrm{p}$.

Palonen, P. \& Lindén, L. 2001. Winter hardiness of micropropagated and conventionally propagated strawberry plants. J. Hortic. Sci. \& Biotechnol. 76: 685-690.

Palonen, P., Lindén, L., Hovi, T., Hytönen, T., Keinänen, L. \& Lilja, P. 2001. Vadelman ja mansikan talvenkestävyyden parantaminen lajikevalinnan ja viljelytekniikan keinoin. Helsingin yliopisto, soveltavan biologian laitoksen julkaisuja n:o 7. p. 1-92.

Sakai, A. \& Larcher, W. 1987. Frost survival of plants. Berlin, Springer-Verlag. 321 p.

Thomas, J.B., Schaalje, G.B. \& Roberts, D.W.A. 1988. Prolonged freezing of dark-hardened seedlings for rating and selection of winter wheats for winter survival ability. Can. J. Plant Sci. 68: 47-55. 